\title{
Harran Ovası'nda Pamukta Zarar Yapan Pembekurt [Pectinophora gossypiella Saund. (Lepidoptera: Gelechiidae)] ve Dikenlikurt [Earias insulana Boisd. (Lepidoptera: Noctuidae)] Larvalarının Kör Kozalardaki Popülasyon Değişimleri
}

Levent ÜNLÜ ${ }^{1}$

Geliş Tarihi: 20.04.2003

\author{
Irfan ÖZTÜRK ${ }^{2}$
}

\begin{abstract}
Özet: Harran Ovası'nda 1999-2001 yılları arasında kör kozalardaki Pembekurt (Pectinophora gossypiella Saund.) ve Dikenlikurt (Earias insulana Boisd.)'un larva popülasyon değişimi incelenmiştir. Bu çalışmada Harran Ovası'nda yaygın olarak yetiştirilen Stonewille-453 pamuk çeşidi kullanıImıştır. Hasattan sonra pamuk bitkileri üzerinde bulunan açmamiş kozalar toplanmış, laboratuvarda içleri kontrol edilerek, kozaların içinde bulunan Pembekurt ve Dikenlikurt'un larva oranlarının popülasyon değişimleri belirlenmiş̧ir. Çalışma sonucunda, her iki zararlının da haftalık popülasyon değişimi arasındaki farkın önemsiz olduğu saptanmıştı,. Larvalı koza oranı, en yüksek 2001 yılında bulunmuş ve Pembekurt larvaları, her üç yılda da Dikenlikurt larvalarından daha yüksek bulunmuştur.
\end{abstract}

Anahtar Kelimeler: dikenlikurt, pembekurt, kör koza, pamuk

\section{The Larval Population Fluctuations of Pink Bollworm [Pectinophora gossypiella Saund. (Lepidoptera: Gelechiidae)] and Spiny Bollworm [Earias insulana Boisd. (Lepidoptera: Noctuidae)] in Blind Bolls on Cotton in Harran Plain}

\begin{abstract}
Field studies were conducted in Harran Plain, Turkey to investigate the larval population fluctuation of Spiny Bollworm (SBW) and Pink Bollworm (PBW) in cotton blind bolls in the periods of 1999-2001. In this study, Stoneville-453 type cotton, which is grown widely in Harran Plain was used. Blind bolls left in the cotton plants after the harvest were collected in order to determine the PBW and SBW larvae population changes in the laboratory by splitting the bolls. Population changes of the larvae ratios of PBW and SBW were determined. At the end of the study, there was no statistically significant changes between weekly larvae population changes of PBW and SBW. The highest ratio of bolls with larvae was determined in 2001 and the larvae ratio of PBW during the experimental periods was higher than SBW larvae.
\end{abstract}

Key Words: spiny bollworm, pink bollworm, blind boll, cotton

Giriş

Pamuk, gerek Harran Ovası gerekse Türkiye için önemli bir endüstri bitkisidir. Harran Ovasi'nda Atatürk barajıyla sulamanın başladığı 1995 yılından günümüze kadar pamuk ekiliş alanları artarak 96000 hektara ulaşmıştır (Anonim 2001).

Lepidoptera takımı içerisinde yer alan Pembekurt (Pectinophora gossypiella Saund.) ve Dikenlikurt (Earias insulana Boisd.), pamuğun önemli zararılırındadır. Pembekurt, dünyanın her tarafına yayılmış olup, 70'den fazla konukçuda zarar yapmaktadır (Noble 1969) Pembekurt'un larvaları ilk önce pamuğun taraklarında, daha sonra da kozalarında beslenmektedir (Roelofs 1978). Kışı olgun larva döneminde pamuk artıkları ve toprakta geçirmektedir (Hennebery ve Clayton 1989). Pembekurt, ilk teşhis edildiği 1843 yılından, günümüze kadar pamuk tarımı yapılan bütün ülkelerde ana zararlı durumuna gelerek, $\% 20$ 'den fazla bir oranda zarar yapmaktadır (Naranjo ve ark. 2002).

Dikenlikurt, Israil'de (Avidov ve Harpaz 1969, Klein ve ark. 1981), Suriye'de (Stam ve Al-Mosa 1990) ve yurdumuzda (Kıray 1964, Ünlü 2001) önemli zararlar oluşturmaktadır. Dikenlikurt yumurtaları açıldıktan sonra çıkan larvaların direkt kozalara girmesinden dolayı, zararlının erken tespit edilmesi, mücadelesinde etkili olmaktadir (Kehat ve ark. 1981).

Pamuğun fenolojisi dikkate alındığında Pembekurt orta ve geç dönem, Dikenlikurt ise geç dönemde zarar yapmaktadır. Bu zararlılar kışı hasattan sonra tarlada kalan kör kozalar içerisinde geçirmektedirler. Bu kör kozalar bir sonraki yıl için enfeksiyon kaynaklarını oluşturmaktadırlar. Kör kozalar incelenerek, bu zararlıların yaptığı zarar ve bir sonraki yıl için popülasyonu tahmin edilebilmektedir.

Bu çalışmada özellikle son yıllarda Harran ovası'nda popülasyonları artan Pembekurt ve Dikenlikurt larvalarının, popülasyon gelişimlerinin belirlenmesi amaçlanmıştır. Zararılırın, Harran Ovası'ndan toplanan kör kozalardaki popülasyon değişimi, larvalı ve larvasız koza oranlar incelenmiştir. Bu sonuçlarla, ileride yapılacak çalışmalara ışık tutulmuş olacaktır.

\footnotetext{
${ }^{1}$ Harran Üniv. Ziraat Fak. Bitki Koruma Bölümü-Şanlıurfa

${ }^{2}$ Harran Üniv. Ziraat Fak. Zootekni Bölümü-Şanlıurfa
} 
ÜNLÜ, L. ve I. ÖZTÜRK, "Harran Ovası'nda pamukta zarar yapan pembekurt [Pectinophora gossypiella Saund. (Lepidoptera: Gelechiidae)] ve dikenlikurt [Earias insulana Boisd. (Lepidoptera: Noctuidae)] larvalarının kör kozalardaki popülasyon değișimleri"

\section{Materyal ve Yöntem}

Harran Ovasi'nda 1999-2001 yıllarında yürütülen çalışmada, ovada yaygın olarak ekimi yapılan Stoneville453 pamuk çeşidi ve bu pamuklarda zararlı olan Dikenlikurt ve Pembekurt zararlılarının larvaları çalışmanın ana materyalini oluşturmuştur.

Harran Ovası'nda pamuğun hasat edilmesinden sonra, birbirinden farklı uzaklıkta seçilen 10 lokaliteden, üc yıl süre ile birer hafta arayla üç farklı periyotta $(5,12$ ve 19 Ekim) tarlalarda kalan kozalardan en az $100^{\prime} \mathrm{er}$ adet toplanmıştır. Kozaların birer hafta arayla toplanmasının sebebi, laboratuvarda yığılmaları engellemek ve iş kolaylığı sağlamasından dolayıdır. Bu kozalar laboratuvara getirilerek içleri açılmış, $E$. insulana ve $P$. gossypiella larvaları ile bulaşık olup olmadıkları kontrol edilmiştir, Toplanan kozaların, larvalı veya larvasız bulaşık koza sayısı ile kozalardan çıkan Dikenlikurt ve Pembekurt'un larva sayıları tespit edilmiştir. Kozaların içlerinden Dikenlikurt ve Pembekurt larvası bulunmuşsa, Larvalı Koza; larva bulunmayıp sadece larva zararı görülmüş ise Larvasız Koza olarak değerlendirilmiştir.
Çalışma, Faktöryel deneme dizaynında Tesadüf Blokları deneme planına göre yürütülmüştür. Araştırmada lokaliteler blok olarak, yıllar A faktörü ve haftalar B faktörü olarak alınmıştır. Lokaliteler için Tukey testi, yıllar ve haftalar için de LSD testi uygulanmıştır. Çalışmada bulaşık larvalı koza sayısı, larvasız koza sayısı, Pembekurt ve Dikenlikurt larva sayıları yüzde oranı olarak alınıp, ArcSin transformasyonları yapılarak, istatistiksel analizleri yapılmıştır.

\section{Bulgular ve Tartışma}

Pembekurt ve Dikenlikurt larvalarının kör kozalardaki popülasyon değişimini araştırmak için yapılan bu çalışmada, toplanan kör kozaların bu zararlılar ile bulaşık olduğu ve larvasız koza sayısının ise, genelde larvalı kozalara göre düşük oranda bulunduğu saptanmıştır.

Çalışma sonucunda elde edilen bulgular Çizelge 110 'da verilmiştir.

Çalışma sonucunda, üç yıla ait haftalık periyotların bulaşıklıık oranları kendi aralarında değerlendirildiğinde,

Çizelge 1. Koruklu'da 1999-2001 yılları arasında kör kozalardaki Pembekurt ve Dikenlikurt'un larva oranları

\begin{tabular}{ccccccc}
\hline Tarih & $\begin{array}{c}\text { Toplanan koza } \\
\text { sayısı }\end{array}$ & $\begin{array}{c}\text { Bulaşık koza } \\
\text { sayısı }\end{array}$ & $\begin{array}{c}\text { Larvalı koza } \\
\text { oranı }\end{array}$ & $\begin{array}{c}\text { Larvasız } \\
\text { koza oranı }\end{array}$ & $\begin{array}{c}\text { Dikénlikurt'un } \\
\text { larva oranı }\end{array}$ & $\begin{array}{c}\text { Pembekurt'un } \\
\text { larva oranı }\end{array}$ \\
\hline 05.10 .1999 & 170 & 72 & 98.61 & 1.39 & 3.36 & 96.64 \\
12.10 .1999 & 124 & 42 & 85.71 & 14.29 & 16.36 & 83.64 \\
19.10 .1999 & 145 & 52 & 76.92 & 23.08 & 9.26 & 90.74 \\
\hline 05.10 .2000 & 105 & 24 & 50.00 & 50.00 & 29.41 & 70.59 \\
12.10 .2000 & 105 & 36 & 77.77 & 22.23 & 2.23 & 97.77 \\
19.10 .2000 & 106 & 53 & 92.45 & 7.55 & 5.89 & 94.11 \\
\hline 05.10 .2001 & 105 & 83 & 96.38 & 3.62 & 27.85 & 72.15 \\
12.10 .2001 & 105 & 93 & 92.47 & 7.53 & 23.39 & 76.61 \\
19.10 .2001 & 105 & 96 & 96.87 & 3.13 & 37.50 & 62.50 \\
\hline
\end{tabular}

Çizelge 2. Akçakale'de 1999-2001 yılları arasında kör kozalardaki Pembekurt ve Dikenlikurt'un larva oranları

\begin{tabular}{ccccccc}
\hline Tarih & $\begin{array}{c}\text { Toplanan koza } \\
\text { sayısı }\end{array}$ & $\begin{array}{c}\text { Bulașık koza } \\
\text { sayısı }\end{array}$ & $\begin{array}{c}\text { Larvalı koza } \\
\text { oranı }\end{array}$ & $\begin{array}{c}\text { Larvasız } \\
\text { koza oranı }\end{array}$ & $\begin{array}{c}\text { Dikenlikurt'un } \\
\text { larva oranı }\end{array}$ & $\begin{array}{c}\text { Pembekurt'un } \\
\text { larva oranı }\end{array}$ \\
\hline 05.10 .1999 & 135 & 24 & 83.33 & 16.67 & 22.23 & 77.77 \\
12.10 .1999 & 155 & 44 & 79.54 & 20.46 & 31.70 & 68.30 \\
19.10 .1999 & 155 & 55 & 81.81 & 18.19 & 31.48 & 68.52 \\
\hline 05.10 .2000 & 120 & 6 & 66.66 & 33.34 & 100.00 & 0.00 \\
12.10 .2000 & 110 & 4 & 75.00 & 25.00 & 100.00 & 0.00 \\
19.10 .2000 & 107 & 6 & 50.00 & 50.00 & 100.00 & 0.00 \\
\hline 05.10 .2001 & 105 & 56 & 76.78 & 23.22 & 71.43 & 28.57 \\
12.10 .2001 & 105 & 56 & 100.00 & 0.00 & 93.75 & 6.25 \\
19.10 .2001 & 105 & 76 & 100.00 & 0.00 & 91.09 & 8.91 \\
\hline
\end{tabular}

Çizelge 3. Fatmakuyu'da 1999-2001 yılları arasında kör.kozalardaki Pembekurt ve Dikenlikurt'un larva oranları

\begin{tabular}{ccccccc}
\hline Tarih & $\begin{array}{c}\text { Toplanan koza } \\
\text { sayısı }\end{array}$ & $\begin{array}{c}\text { Bulaşık koza } \\
\text { sayısı }\end{array}$ & $\begin{array}{c}\text { Larvalı koza } \\
\text { orani }\end{array}$ & $\begin{array}{c}\text { Larvasız } \\
\text { koza oranı }\end{array}$ & $\begin{array}{c}\text { Dikenlikurt'un } \\
\text { larva oranı }\end{array}$ & $\begin{array}{c}\text { Pembekurt'un } \\
\text { larva oranı }\end{array}$ \\
\hline 05.10 .1999 & 200 & 87 & 64.37 & 35.63 & 31.51 & 68.49 \\
12.10 .1999 & 210 & 75 & 62.66 & 37.34 & 58.93 & 41.07 \\
19.10 .1999 & 204 & 56 & 66.07 & 33.93 & 40.43 & 59.57 \\
\hline 05.10 .2000 & 156 & 17 & 70.58 & 29.42 & 100.00 & 0.00 \\
12.10 .2000 & 120 & 17 & 64.70 & 35.30 & 83.33 & 16.67 \\
19.10 .2000 & 105 & 35 & 62.86 & 37.14 & 95.83 & 4.17 \\
\hline 05.10 .2001 & 105 & 45 & 88.88 & 11.12 & 88.00 & 12.00 \\
12.10 .2001 & 105 & 56 & 94.64 & 5.36 & 83.33 & 12.12 \\
19.10 .2001 & 105 & 64 & 100.00 & 0.00 & 95.83 & 10.00 \\
\hline
\end{tabular}


Çizelge 4. Parapara'da 1999-2001 yılları arasında kör kozalardaki Pembekurt ve Dikenlikurt'un larva oranları

\begin{tabular}{ccccccc}
\hline Tarih & $\begin{array}{c}\text { Toplanan koza } \\
\text { sayısı }\end{array}$ & $\begin{array}{c}\text { Bulaşık koza } \\
\text { sayısı }\end{array}$ & $\begin{array}{c}\text { Larvalı koza } \\
\text { oranı }\end{array}$ & $\begin{array}{c}\text { Larvasız } \\
\text { koza oranı }\end{array}$ & $\begin{array}{c}\text { Dikenlikurt'un } \\
\text { larva oranı }\end{array}$ & $\begin{array}{c}\text { Pembekurt'un } \\
\text { larva oranı }\end{array}$ \\
\hline 05.10 .1999 & 115 & 9 & 77.78 & 22.22 & 50.00 & 50.00 \\
12.10 .1999 & 105 & 24 & 91.66 & 8.34 & 28.00 & 72.00 \\
19.10 .1999 & 115 & 27 & 55.55 & 44.45 & 27.78 & 72.22 \\
\hline 05.10 .2000 & 105 & 11 & 54.54 & 45.46 & 14.28 & 85.72 \\
12.10 .2000 & 108 & 10 & 70.00 & 30.00 & 22.22 & 77.78 \\
19.10 .2000 & 110 & 13 & 92.30 & 7.70 & 18.75 & 81.25 \\
\hline 05.10 .2001 & 105 & 70 & 90.00 & 10.00 & 36.45 & 63.55 \\
12.10 .2001 & 105 & 73 & 97.26 & 2.74 & 39.06 & 60.94 \\
19.10 .2001 & 105 & 82 & 100.00 & 0.00 & 21.02 & 78.98 \\
\hline
\end{tabular}

Çizelge 5. Nusretiye'de 1999-2001 yılları arasında kör kozalardaki Pembekurt ve Dikenlikurt'un larva oranlar

\begin{tabular}{cccccrr}
\hline Tarih & $\begin{array}{c}\text { Toplanan koza } \\
\text { sayısı }\end{array}$ & $\begin{array}{c}\text { Bulaşık koza } \\
\text { sayısı }\end{array}$ & $\begin{array}{c}\text { Larvalı koza } \\
\text { oranı }\end{array}$ & $\begin{array}{c}\text { Larvasız } \\
\text { koza oranı }\end{array}$ & $\begin{array}{c}\text { Dikenlikurt'un } \\
\text { larva oranı }\end{array}$ & $\begin{array}{c}\text { Pembekurt'un } \\
\text { larva oranı }\end{array}$ \\
\hline 05.10 .1999 & 110 & 15 & 73.33 & 26.67 & 36.36 & 63.64 \\
12.10 .1999 & 108 & 20 & 60.00 & 40.00 & 46.66 & 53.34 \\
19.10 .1999 & 108 & 22 & 77.27 & 22.73 & 25.00 & 75.00 \\
\hline 05.10 .2000 & 105 & 2 & 50.00 & 50.00 & 100.00 & 0.00 \\
12.10 .2000 & 107 & 6 & 66.66 & 33.34 & 0.00 & 100.00 \\
19.10 .2000 & 106 & 19 & 63.15 & 36.85 & 46.15 & 53.85 \\
\hline 05.10 .2001 & 105 & 23 & 91.30 & 8.70 & 75.00 & 25.00 \\
12.10 .2001 & 105 & 36 & 97.22 & 2.78 & 42.37 & 57.63 \\
19.10 .2001 & 105 & 59 & 100.00 & 0.00 & 48.98 & 51.02 \\
\hline
\end{tabular}

Çizelge 6. Mutlukaya'da 1999-2001 yılları arasında kör kozalardaki Pembekurt ve Dikenlikurt'un larva oranları

\begin{tabular}{ccccccc}
\hline Tarih & $\begin{array}{c}\text { Toplanan koza } \\
\text { sayısı }\end{array}$ & $\begin{array}{c}\text { Bulaşık koza } \\
\text { sayısı }\end{array}$ & $\begin{array}{c}\text { Larvalı koza } \\
\text { oranı }\end{array}$ & $\begin{array}{c}\text { Larvasız } \\
\text { koza oranı }\end{array}$ & $\begin{array}{c}\text { Dikenlikurt'un } \\
\text { larva oranı }\end{array}$ & $\begin{array}{c}\text { Pembekurt'un } \\
\text { larva oranı }\end{array}$ \\
\hline 05.10 .1999 & 110 & 65 & 81.54 & 18.46 & 5.44 & 94.56 \\
12.10 .1999 & 109 & 82 & 91.46 & 8.54 & 4.94 & 95.06 \\
19.10 .1999 & 108 & 67 & 83.58 & 16.42 & 6.93 & 93.07 \\
\hline 05.10 .2000 & 104 & 10 & 80.00 & 20.00 & 25.00 & 75.00 \\
12.10 .2000 & 105 & 29 & 82.76 & 17.24 & 0.00 & 100.00 \\
19.10 .2000 & 104 & 27 & 85.18 & 14.82 & 0.00 & 100.00 \\
\hline 05.10 .2001 & 105 & 96 & 90.63 & 9.37 & 10.05 & 89.95 \\
12.10 .2001 & 105 & 104 & 99.04 & 0.96 & 11.55 & 88.45 \\
19.10 .2001 & 105 & 98 & 98.98 & 1.02 & 7.55 & 92.45 \\
\hline
\end{tabular}

Çizelge 7. Yardımcı'da 1999-2001 yılları arasında kör kozalardaki Pembekurt ve Dikenlikurt'un larva oranları

\begin{tabular}{ccccccc}
\hline Tarih & $\begin{array}{c}\text { Toplanan koza } \\
\text { sayısı }\end{array}$ & $\begin{array}{c}\text { Bulaşık koza } \\
\text { sayısı }\end{array}$ & $\begin{array}{c}\text { Larvalı koza } \\
\text { oranı }\end{array}$ & $\begin{array}{c}\text { Larvasız } \\
\text { koza oranı }\end{array}$ & $\begin{array}{c}\text { Dikenlikurt'un } \\
\text { larva oranı }\end{array}$ & $\begin{array}{c}\text { Pembekurt'un } \\
\text { larva oranı }\end{array}$ \\
\hline 05.10 .1999 & 110 & 78 & 100.00 & 0.00 & 0.51 & 99.49 \\
12.10 .1999 & 110 & 91 & 94.50 & 5.50 & 3.67 & 96.33 \\
19.10 .1999 & 107 & 69 & 85.50 & 14.50 & 1.52 & 98.48 \\
\hline 05.10 .2000 & 105 & 17 & 52.94 & 47.06 & 22.23 & 77.77 \\
12.10 .2000 & 107 & 40 & 87.50 & 12.50 & 4.35 & 95.65 \\
19.10 .2000 & 105 & 60 & 90.00 & 10.00 & 8.05 & 91.95 \\
\hline 05.10 .2001 & 105 & 75 & 89.33 & 10.67 & 43.70 & 56.30 \\
12.10 .2001 & 105 & 89 & 98.87 & 1.13 & 11.87 & 88.13 \\
19.10 .2001 & 105 & 88 & 96.59 & 3.41 & 23.43 & 76.57 \\
\hline
\end{tabular}

Çizelge 8. Uğurlu'da 1999-2001 yılları arasında kör kozalardaki Pembekurt ve Dikenlikurt'un larva oranları

\begin{tabular}{ccccccc}
\hline Tarih & $\begin{array}{c}\text { Toplanan koza } \\
\text { sayısı }\end{array}$ & $\begin{array}{c}\text { Bulaşık koza } \\
\text { sayısı }\end{array}$ & $\begin{array}{c}\text { Larvalı koza } \\
\text { oranı }\end{array}$ & $\begin{array}{c}\text { Larvasız } \\
\text { koza oranı }\end{array}$ & $\begin{array}{c}\text { Dikenlikurt'un } \\
\text { larva oranı }\end{array}$ & $\begin{array}{c}\text { Pembekurt'un } \\
\text { larva oranı }\end{array}$ \\
\hline 05.10 .1999 & 105 & 43 & 93.02 & 6.98 & 0.00 & 100.00 \\
12.10 .1999 & 105 & 78 & 92.31 & 7.69 & 2.74 & 97.26 \\
19.10 .1999 & 114 & 66 & 92.42 & 7.58 & 1.59 & 98.41 \\
\hline 05.10 .2000 & 105 & 14 & 85.71 & 14.29 & 13.34 & 86.66 \\
12.10 .2000 & 110 & 24 & 75.00 & 25.00 & 9.10 & 90.90 \\
19.10 .2000 & 105 & 39 & 69.23 & 30.77 & 10.80 & 89.20 \\
\hline 05.10 .2001 & 105 & 60 & 83.33 & 16.67 & 21.52 & 78.48 \\
12.10 .2001 & 105 & 58 & 96.55 & 3.45 & 37.98 & 62.02 \\
19.10 .2001 & 105 & 56 & 94.64 & 5.36 & 50.00 & 50.00 \\
\hline
\end{tabular}


ÜNLÜ, L. ve I. ÖZTÜRK, "Harran Ovasi'nda pamukta zarar yapan pembekurt [Pectinophora gossypiella Saund. (Lepidoptera: Gelechiidae)] ve dikenlikurt [Earias insulana Boisd. (Lepidoptera: Noctuidae)] larvalarının kör kozalardaki popülasyon değişimleri"

Çizelge 9. Yenice'de 1999-2001 yıllanı arasında kör kozalardaki Pembekurt ve Dikenlikurt'un larva oranları

\begin{tabular}{ccrrrrr}
\hline Tarih & $\begin{array}{c}\text { Toplanan koza } \\
\text { sayısı }\end{array}$ & $\begin{array}{c}\text { Bulaşık koza } \\
\text { sayısı }\end{array}$ & $\begin{array}{c}\text { Larvalı koza } \\
\text { orani }\end{array}$ & $\begin{array}{c}\text { Larvasız } \\
\text { koza oranı }\end{array}$ & $\begin{array}{c}\text { Dikenlikurt'un } \\
\text { larva oranı }\end{array}$ & $\begin{array}{c}\text { Pembekurt'un } \\
\text { larva oranı }\end{array}$ \\
\hline 05.10 .1999 & 105 & 38 & 97.36 & 2.64 & 0.00 & 100.00 \\
12.10 .1999 & 110 & 61 & 90.16 & 9.84 & 1.08 & 98.92 \\
19.10 .1999 & 110 & 66 & 90.90 & 9.10 & 3.81 & 96.19 \\
\hline 05.10 .2000 & 107 & 0 & 0.00 & 0.00 & 0.00 & 0.00 \\
12.10 .2000 & 105 & 1 & 100.00 & 0.00 & 0.00 & 0.00 \\
19.10 .2000 & 105 & 4 & 75.00 & 25.00 & 40.00 & 60.00 \\
\hline 05.10 .2001 & 105 & 38 & 73.68 & 26.32 & 46.34 & 53.66 \\
12.10 .2001 & 105 & 36 & 97.22 & 2.78 & 71.79 & 28.21 \\
19.10 .2001 & 105 & 54 & 96.30 & 3.70 & 39.71 & 60.29 \\
\hline
\end{tabular}

Çizelge 10. Çavdarlı'da 1999-2001 yılları arasında kör kozalardaki Pembekurt ve Dikenlikurt'un larva oranları

\begin{tabular}{ccccccc}
\hline Tarih & $\begin{array}{c}\text { Toplanan koza } \\
\text { sayısı }\end{array}$ & $\begin{array}{c}\text { Bulaşık koza } \\
\text { sayısı }\end{array}$ & $\begin{array}{c}\text { Larvalı koza } \\
\text { oranı }\end{array}$ & $\begin{array}{c}\text { Larvasız } \\
\text { koza oranı }\end{array}$ & $\begin{array}{c}\text { Dikenlikurt'un } \\
\text { larva oranı }\end{array}$ & $\begin{array}{c}\text { Pembekurt'un } \\
\text { larva oranı }\end{array}$ \\
\hline 05.10 .1999 & 120 & 17 & 100.00 & 0.00 & 35.29 & 64.71 \\
12.10 .1999 & 110 & 32 & 87.50 & 12.50 & 24.32 & 75.68 \\
19.10 .1999 & 120 & 33 & 69.70 & 30.30 & 35.29 & 64.71 \\
\hline 05.10 .2000 & 110 & 6 & 66.66 & 33.34 & 20.00 & 80.00 \\
12.10 .2000 & 105 & 12 & 58.33 & 41.67 & 22.22 & 77.78 \\
19.10 .2000 & 105 & 11 & 90.90 & 9.10 & 0.00 & 100.00 \\
\hline 05.10 .2001 & 105 & 29 & 65.51 & 34.49 & 4.00 & 96.00 \\
12.10 .2001 & 105 & 53 & 98.11 & 1.89 & 24.71 & 75.29 \\
19.10 .2001 & 105 & 52 & 94.23 & 5.77 & 28.24 & 71.76 \\
\hline
\end{tabular}

bulaşık larvalı koza oranlarında haftalar ilerledikçe artmalar saptanmış ve bu artışın önemli olduğu, uygulanan LSD testi sonucunda belirlenmiştir $(P<0.01)$ Tüm üç yılın ilk haftalarındaki en düşük bulaşık larval koza oranı $\% 62.75$ olurken, en yüksek oranın (\%70.15) ikinci haftada meydana geldiği ve ikinci haftanın bulaşık larvalı koza oranının üçüncü haftanın oranı $(\% 69.58)$ ile arasında fark olmadığı saptanmıştır.

Yillar itibariyle bulaşık larvalı koza oranı incelendiğinde, yıllar arasında farkın önemli olduğu belirlenmiştir $(P<0.01)$. Bulaşık larvalı koza oranı, en yüksek üçüncü yılda (2001) $\% 77.46$ olarak bulunmuştur. Daha sonra birinci yıl (1999) gelmektedir. Bu yıldaki bulaşık larvalı koza oranı $\% 67.38$ oranında gerçekleşmiştir. En düşük oran ise, ikinci yılda (2000) $\% 57.64$ oranında ortaya çıkmıştır. Yıllar ilerledikçe, bulașık larvalı koza oranında artış gözlenirken (sırasıyla $\% 67.38, \% 57.64$ ve $\% 77.46$ ), ikinci yıldaki larvalı koza oranında, pamuğun iklim şartlarının sebep olduğu geç ekiminden dolayı düşǔk oranda saptanmıştır.

Dikenlikurt larva oranları incelendiğinde, blok olarak değeriendirilen lokaliteler arasında önemli bir farkın olduğu gözlenmiştir $(P<0.01)$. Ayrıca Dikenlikurt larva oranlarının yıllık popülasyon değişimleri arasındaki fark da önemli bulunmuştur $(P<0.01)$. Dikenlikurt larva oranı en yüksek, Akçakale ve Fatmakuyu lokalitelerinde sırasıyla \%63.59 ve $\% 63.20$ oranında saptanmıştır. Bunun sebebi olarak, bu lokalitelerin Suriye sınırına çok yakın olması gösterilebilir. Stam ve Al-Mosa (1990)'nın Dikenlikurt'un Suriye pamuklarında ana zararlı olduğunu belirtmesinden dolayı, bu zararlının Suriye'den bu alanlara kolayca geçmiş olması sonucuna varılabilir. Dikenlikurt larva oranlarında, yıllar ilerledikçe artışlar gözlenmiştir. Larva oranı, en yüksek 2000 ve 2001 yillarında sırasıyla $\% 33.57$ ve $\% 41.07$ oranında olup, bu yıllar arasındaki fark önemsiz bulunmuştur. En düşük larva oranı ise, 1999 yılında \%23.05 olarak gerçekleşmiştir. Dikenlikurt, larva oranlarının haftalık popülasyon değişimleri arasındaki farkın önemsiz çıkmasından dolayı $(P>0.05)$, çoklu karşılaştırma testi uygulanmamıştır.

Pembekurt larva oranları incelendiğinde, blok olarak değerlendirilen lokaliteler arasında önemli bir farkın olduğu gözlenmiştir $(P<0.01)$. Ayrıca Pembekurt larva oranı yıllara göre değerlendirildiğinde de fark önemli bulunmuştur $(P<0.01)$. Pembekurt larva oranı en yüksek, Harran Ovası'nın merkezi sayılacak Mutlukaya, Yardımcı ve Çavdarlı lokalitelerinde sırasıyla \%76.01, \%71.18 ve $\% 69.37$ oranında bulunmuştur. En düşük larva oranı ise Dikenlikurt'un yoğun olarak görüldüğü Akçakale ve Fatmakuyu lokalitelerinde sırasıyla $\% 26.40$ ve $\% 26.79$ oranında saptanmıştır. Pembekurt larva oranlarında, Dikenlikurt'un tersine en yüksek larva popülasyonu 1999 yilında $\% 66.49$ oranında bulunurken, 2000 ve 2001 yılları arasında larva oranı bakımından bir farkın olmadığı ve larva popülasyonunun sırasıyla $\% 50.43$ ve $\% 48.92$ oranında olduğu bulunmuştur $(P<0.01)$. Bu sonuçlar, Dikenlikurt larvalarının oranı artarken, Pembekurt'un larva oranında azalma, yine Dikenlikurt larvalarının oranı azalırken, Pembekurt'un larva oranında artış olduğunu göstermiştir. Pembekurt, larva oranlarının haftalık popülasyon değişimleri arasındaki farkın önemsiz çıkmasından dolayı $(P>0.05)$, çoklu karşılaştırma testi uygulanmamıştır.

Sonuç olarak, larvalı koza oranı en fazla 2001 yılında bulunmuştur. Pembekurt larvaları, her üç yılda da Dikenlikurt larvalarına göre, daha yüksek oranda bulunmuştur. Pembekurt larva oranları, 1999 yilinda en 
yüksek oranda bulunurken, diğer iki yılda düşük oranda gerçekleşmiştir. Dikenlikurt larva oranının ise, 2001 yılında diğer yıllara göre daha yüksek oranda olduğu saptanmıştır. Her iki zararlının da haftalık popülasyon değişiminin arasındaki farkın önemsiz olduğu saptanmıştır. Pembekurt larva oranlarının Dikenlikurt larva oranlarına göre yüksek olmasının sebepleri; yöre çiftçisinin bu zararlıyı tanımaması, kendi tohumluğunu kendi tarlasından temin etmesi, bulaşık tohumları sawgen makinalarından geçirmeden ve fumige edilmeden direkt tarlaya ekmesi şeklinde sıralanabilmektedir.

\section{Kaynaklar}

Anonim, 2001. Şanlıurfa Tarım İ Müdürlüğü Proje ve Istatistik Şube Müdürlüğü Kayıtları.

Avidov, Z. and I. Harpaz, 1969. Plant Pests of Israel. Israel Universities Press, Jeruselam.

Henneberry, T. J. and T. E. Clayton, 1989. Oviposition patterns, percent egg hatch and larval mortality of Pink Bollworm (Lepidoptera: Gelechiidae) on cotton plants. J. Econ. Entomol., 82 (3) 932-934.

Kehat, M., S. Gothilf, E. Dunkelblum and S. Greenberg, 1981. Captures of Earias insulana males in water traps and dry funnel traps baited with synthetic pheromone or virgin females. Phytoparasitica, 9, 149-151.

Kıray, Y. 1964. Çukurova Bölgesi pamukları ve diğer kültür bitkilerinde zarar yapan Earias insulana (Boisd.) böceğinin biyolojisi ve mücadelesi üzerinde araştırmalar. Doktora Tezi. Kemal Matbaası, s. 119, Adana.

Klein, M., A. Navon, M. Andreadou and S. Keren, 1981. Development of an artificial diet for mass rearing of the spiny bollworm, Earias insulana. Phytoparasitica, 9, 145148.
Naranjo, S. E., Jr. G. D. Butler and T. J. Henneberry, 2002. A bibliography of the pink bollworm, Pectinophora gossypiella (Saunders). U. S. Dept. Agric., Agric. Res. Serv., Bibliographies and Literature of Agriculture No. 136.

Noble, L. W. 1969. Fifty years of research on the pink bollworm in the United States. USDA Agric. Handb. 357: 62pp. "In: Chu, C. C., T. J. Henneberry, R. C. Weddle, E. T. Natwick, J. R. Carson, C. Valenzuela, S. L. Birdsall, R. T. Staten 1996. Reduction of Pink Bollworm (Lepidoptera: Gelechiidae) populations in the Imperial valley, California, Following Mandatory short-season cotton management systems." J. Econ. Entomol. 89, 175-182.

Roelofs, W. L. 1978. Chemical control of insects by pheromones, pp. 419-464. In: M. Rockstein [Ed.], Bio-chemistry of insects. Academic, New York.

Stam, P. A. and H. Al-Mosa, 1990. The role of predators and parasites in controlling populations of Earias insulana, Heliothis armigera and Bemisia tabaci on cotton in the Syrian Arap Republic. Entomophaga, 35, 315-327.

Ünlü, L. 2001. Şanlıurfa'da pamuk alanlarında zararlı olan lepidoptera türlerinin saptanması, popülasyon değişimleri, doğal düșmanları ile dikenlikurt (Earias insulana Boisd.)'un biyolojisi ve bitki fenolojisi arasındaki ilişkilerin belirlenmesi. Çukurova Üniv. Fen Bilimleri Enstitüsü Bitki Koruma Anabilim Dalı, 110 s., Doktora Tezi, Adana.

\author{
İletişim adresi: \\ Levent ÜNLÜ \\ Harran Üniversitesi Ziraat Fakültesi \\ Bitki Koruma Bölümü 63200-Şanlıurfa \\ Tel: $04142470384 / 2381$ \\ E-Mail: ulevent@yahoo.com
}

